\title{
Super Antibiotics: Part V. Doxycycline
}

\author{
Ilia Brondz \\ Norwegian Drug Control and Drug Discovery Institute (NDCDDI), Ski, Norway \\ Email: ilia.brondz@gmail.com
}

How to cite this paper: Brondz, I. (2017) Super Antibiotics: Part V. Doxycycline. Voice of the Publisher, 3, 53-58. https://doi.org/10.4236/vp.2017.34006

Received: December 6, 2017 Accepted: December 19, 2017 Published: December 22, 2017

Copyright $\odot 2017$ by author and Scientific Research Publishing Inc. This work is licensed under the Creative Commons Attribution-NonCommercial-ShareAlike International License (CC BY-NC-SA 4.0). http://creativecommons.org/licenses/by-nc-sa/4.0/ cc) (i) (2) Open Access

\begin{abstract}
This paper is partly a case report and partly a research investigation. It describes a case of injury to a patient who was being treated with a combination of doxycycline and amoxicillin as a consequence of working in daylight in summer 2017. The injury manifested as a cataract to his exposed left eye, while his right eye, which was covered by a bandage that also covered parts of his face, was healthy. Subsequently, similar effects were observed in the laboratory in albino rabbits subjected to conditions simulating those described by the patient. Additional investigations and observations of possible injuries to the eyes resulting from the combination of photosensitizing substances and sunlight should be performed.
\end{abstract}

\section{Keywords}

Antibiotics, Doxycycline, Amoxicillin, Photosensitizing substances, Case of Injury, Eyes

\section{Introduction}

The Super Antibiotics [1] [2] [3] [4] series of papers describe the new discoveries in this important field. The present case involved doxycycline and amoxicillin. Although doxycycline can be compared to the fourth-generation antibiotics belonging to the penicillin family, however it is a tetracycline, not a penicillin. The structure of doxycycline is shown in Figure 1. The structure of amoxicillin, which is a penicillin, is shown in Figure 2.

Both these antibiotics are used to treat a number of infections with different etiologies. Both are used for treatment of skin infections, but have rarely been used together. Among the rare side effects that have been described for amoxicillin is sensitivity to light and sound. Among the common side effects that have been described for doxycycline is an increased risk of sunburn: "Photosensitivity, manifested by an exaggerated sunburn reaction, reported with tetracyclines" 
<smiles>C[C@@H]1[C@H]2C(=C(O)[C@]3(O)C(=O)C(C(N)=O)C(O)[C@@H](N(C)C)[C@H]3[C@H]2O)C(=O)c2c(O)cccc2[C@@H]1C</smiles>

\section{$(4 S, 4 \mathrm{a} R, 5 S, 5 \mathrm{a} R, 6 R, 12 \mathrm{a} S)-4-($ dimethylamino)- $3,5,10,12,12 a-p e n t a h y d r o x y-6-m e t h y l-1,11-$ dioxo-1,2,3,4,4a,5,5a,6,11,12a- decahydrotetracene-2-carboxamide}

Figure 1. Structure and IUPAC nomenclature for doxycycline.<smiles>CC1(C)S[C@@H]2C(NC(=O)[C@@H](N)c3ccc(O)cc3)C(=O)N2[C@H]1C(=O)O</smiles>

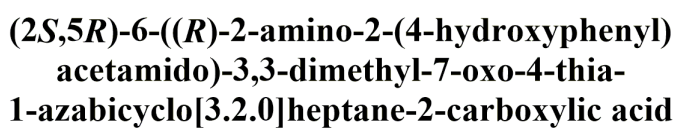

Figure 2. Structure and IUPAC nomenclature for amoxicillin.

[5] [6] [7]. There has been no widespread dissemination to physicians and the public of information about possible injuries from sun light exposure to eyes during treatment with either doxycycline or amoxicillin.

\section{Case}

The patient was a 55-year-old man, $180 \mathrm{~cm}$ tall, weight $76 \mathrm{~kg}$, in good health, and self-reported as usually healthy. He is a self-employed professional carpenter and owner of a one-man business. He received an injury to the right side of his forehead, eyebrow, and cheek during construction work. He did not care for the wound for two days. On the third day, the wound appeared very swollen. Laboratory analysis showed that it was infected with mixed microflora from dust. His physician prescribed amoxicillin and doxycycline because, in addition to the mixed bacterial infection, the wounds were also infected with mycoplasma. $\mathrm{He}$ received on the right side of face a bandage, which also covered right eye. The patient was given sick leave until the infection was controlled, but because he was self-employed, time pressure and the lucrative payment for the job meant that he decided to continue working. His injury did not prevent him working 
with his hands. The antibiotic treatment lasted for 10 days, after which the wound was clean and closed completely. Two to three weeks later, the patient noticed a weakness in the vision in his left eye. He visited an oculist, who discovered the cataract in his left eye (Figure 3(a) and Figure 3(b)).

\section{Preliminary Laboratory Investigation}

Twelve New Zealand white rabbits were used as experimental animals. The animals were divided into four groups of three. The animals' eyes were examined before the start of experiment to detect any cataracts. The right eye of all rabbits was protected from sunlight with a bandage. The first group was the control that did not receive any medication, the second group received only amoxicillin at the same concentration per kg body weight as was given to the patient, the third group received only doxycycline at the same concentration per kg body weight as was given to the patient, and the fourth group received both amoxicillin and

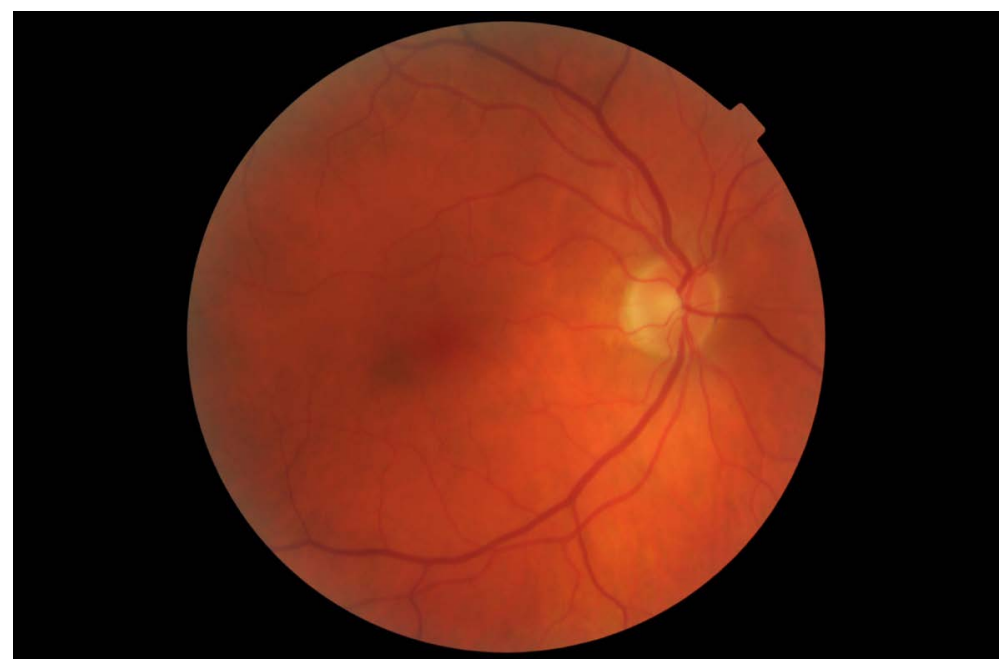

(a)

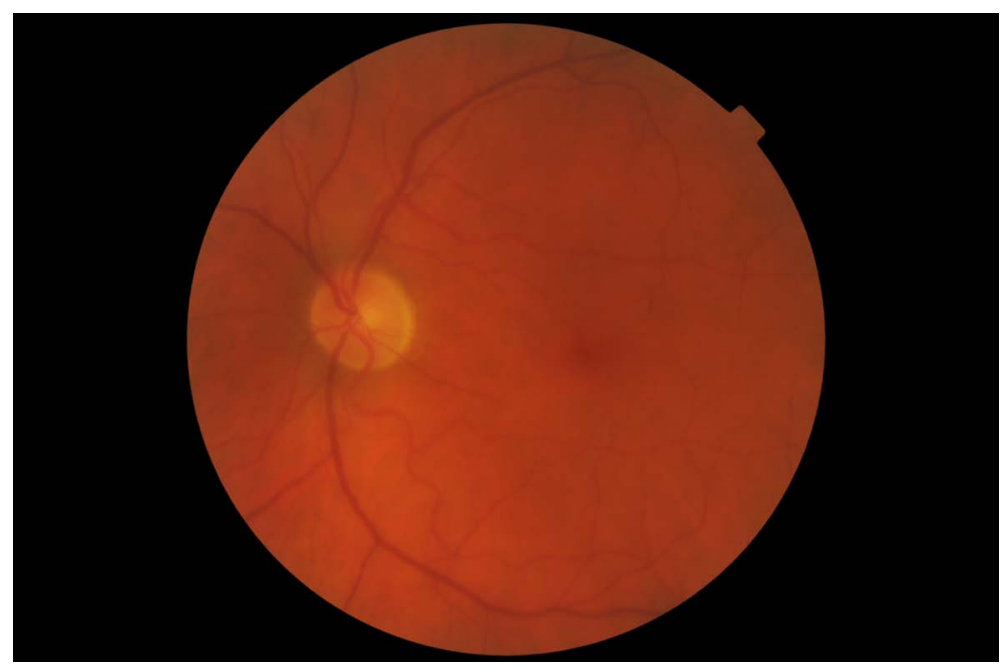

(b)

Figure 3. (a) The patient's right eye; (b) The patient's left eye. 
doxycycline at the concentrations per kg body weight that were given to the patient. The duration of medication of the experiment was the same as those for the patient.

All rabbits were allowed to run free in a clearing in the forest where no trees gave shadow. The animals' eyes were monitored for three months before being used for histological analysis. The results were analyzed by comparison of the left and right eyes of the same animal. Because of the small number of animals in each group, meaningful statistical analysis was not possible, so only qualitative observations are reported. The laboratory investigation in details together with statistics for larger cohorts will be described elsewhere.

The first group showed no changes that could be defined as cataract development. The second group showed some slight differences between the left and right eyes, but these were too small to be regarded as injury. The third group showed some differences between left and right eyes that could be related to cataract development. The fourth group showed marked differences between the left and right eyes that could be related to cataract development. Histological analysis of all eyes is in progress to evaluate possible injury to the retina.

\section{Discussion}

We were unable to perform meaningful statistical analysis because of the small number of animals in the groups, and because the time of observation after exposure was only three months. Therefore, only qualitative observations could be reported. These include:

1) A short period of sunlight exposure by itself has no detectable effect on cataract initiation.

2) Photosensitizing agents can be the trigger for cataract development in intense sunlight.

3) The effects of amoxicillin alone on cataract development in sunlight should be supported in a larger group of animals to determine its statistical significance.

4) Doxycycline alone caused a detectable increase in cataract development in sunlight; however, more experiments should be done to confirm this finding.

5) The effects of a combination of amoxicillin with doxycycline in causing cataract development in sunlight are obvious.

6) A possible influence of photosensitizing agents, such as amoxicillin and doxycycline, and other on development of sunlight-related injuries to the retina cannot be ignored.

We strongly hope that authorities, pharmacopeia committees, editors of professional journals and manufacturers of pharmaceutical products will not react to this discovery in the same way that they reacted to previous reports of the significant elevation of toxicity of contaminated primaquine (mixture of primaquine/quinocide) in comparison with pure primaquine, and will not act to suppress the findings of this paper or falsify the data as described previously [8]-[14]. 


\section{Conclusions}

Based on our qualitative observations, we can draw the following conclusions:

1) Pharmaceutical product manufacturers should provide warnings for photosensitizing drugs that should include the possibility of eye injuries such as cataracts and retinal damage.

2) The consumers of products that include photosensitizing drugs, food dyes, or additives with photosensitizing properties, should be clear informed about the consequences of being in sunlight. The use of sunglasses should be recommended to prevent injuries to the eyes resulting from the combination of photosensitizing substances and sunlight.

3) To confirm our results, additional investigations and observations of possible injuries to the eyes resulting from the combination of photosensitizing substances and sunlight should be performed using larger cohorts.

\section{References}

[1] Brondz, I. (2016) Super Antibiotics, Part I. Hyperforin. Voice of the Publisher, 2, 19-27. https://doi.org/10.4236/vp.2016.24004

[2] Brondz, I. (2016) Super Antibiotics, Part II. Hyperforin, Mass Spectroscopy (MS) and Gas Chromatography-Mass Spectrometry (GC-MS), Evidence of Permeability of the Blood-Testis Barrier (BTB) and the Blood-Brain Barrier (BBB) to Hyperforin. International Journal of Analytical Mass Spectrometry and Chromatography, 4, 66-73. https://doi.org/10.4236/ijamsc.2016.44007

[3] Brondz, I. (2017) Super Antibiotics: Part III. Hyperforin, Revision of the Relative and Absolute Stereochemistry Presented by Bystrov et al. Voice of the Publisher, 3 , 15-24. https://doi.org/10.4236/vp.2017.32002

[4] Brondz, I. (2017) Super Antibiotics, Part IV. Hyperforin, Relative and Absolute Stereochemistry Elucidated by Gas-Chromatography Mass-Spectrometry with Supersonic Molecular Beams. International Journal of Analytical Mass Spectrometry and Chromatography, 5, 70-85. https://doi.org/10.4236/ijamsc.2017.53005

[5] Doxycycline Calcium. https://www.drugs.com/monograph/doxycycline-calcium.html

[6] Pfizer (2001) Vibramycin Calcium (Doxycycline Calcium) Syrup, Vibra-Mycinhyclate (Doxycycline Hyclate) Capsules, Vibramycin Mono-Hydrate (Doxycycline Monohydrate) for Oral Suspension, Vibra-Tabs (Doxycycline Hyclate) Film-Coated Tablets Prescribing Information. Pfizer, New York.

[7] Pfizer (2002) Vibramycinhyclate (Doxycycline Hyclate) Intravenous Prescribing Information (Dated Mar 1991). In: Physicians' Desk Reference, 56th Edition, Medical Economics Company Inc., Montvale, 2737-2738.

[8] Brondz, I., Mantzilas, D., Klein, U., Ekeberg, D., Hvattum, E., Lebedeva, M.N. Mikhailitsyn, F.S., Souleimanov, G.D. and Røe, J. (2004) Nature of the Main Contaminant in the Anti-Malaria Drug Primaquine Diphosphate: A Qualitative Isomer Analysis. Chromatography B: Biomedical Sciences and Applications, 800, 211-223. https://doi.org/10.1016/j.jchromb.2003.09.042

[9] Brondz, I., Klein, U., Ekeberg, D., Mantzilas, D., Hvattum, E., Schultz, H. and Mikhailitsyn, F.S. (2005) Nature of the Main Contaminant in the Anti-Malaria Drug Primaquine Diphosphate: GC-MS Analysis. Asian Journal of Chemistry, 17, 1678-1688. 
[10] Brondz, I. (2012) Analytical Methods in Quality Control of Scientific Publications, American Journal of Analytical Chemistry, 3, 443-447. https://doi.org/10.4236/ajac.2012.36058

[11] Brondz, I. (2013) Analytical Methods in Quality Control of Scientific Publications Part II the Authors', Reviewers', Editors' Responsibility and the Publishers' Authority. International Journal of Analytical Mass Spectrometry and Chromatography, 1, 81-89. https://doi.org/10.4236/ijamsc.2013.12010

[12] Brondz, I. (2014) Analytical Methods in Quality Control of Scientific Publications Part III: Publishers' Ethics and Editors' Complicity. International Journal of Analytical Mass Spectrometry and Chromatography, 2, 77-102. https://doi.org/10.4236/ijamsc.2014.23008

[13] Brondz, I. (2014) Analytical Methods in Quality Control of Scientific Publications Part IV: Fraud Ordered by the Pharmaceutical Industry. International Journal of Analytical Mass Spectrometry and Chromatography, 2, 103-112. https://doi.org/10.4236/ijamsc.2014.24009

[14] Brondz, I. (2015) Analytical Methods in the Quality Control of Scientific Publications Part V: The Fraud of Pseudoscientists Based on False Measurements and Method Development. International Journal of Analytical Mass Spectrometry and Chromatography, 3, 25-31. https://doi.org/10.4236/ijamsc.2015.32003 